\title{
Fatal varicella: Atypical presentation and stabbing outcome
}

\section{Alaoui Aicha Elharrouni, Hanane Baybay, Chaymae Jroundi, Zakia Douhi, Sara Elloudi, Fatima Zahra Mernissi}

Department of Dermatology, University Hospital Hassan II Fez, Morocco

Corresponding author: Dr. Alaoui Aicha Elharrouni, E-mail: ealaouiaicha@gmail.com

\begin{abstract}
Varicella is a cosmopolitan communicable disease caused by varicella- zoster virus (VZV) characterized by papulovesicular rash and fever. Severe complications and death may occur in pregnancy, in newborns, in adults, and in immunocompromised children. We report a case of CIVD with during fatal varicella in an immunocompromised 13- month-old child.
\end{abstract}

Key words: Fatal varicella; Atypical presentation; Civd; Mortality

\section{INTRODUCTION}

Infection with varicella-zoster virus (VZV) in oncology patients can result in severe disease with an increased risk of morbidity and mortality. Among patients on cancer chemotherapy, only nonimmune persons are considered to be susceptible to varicella [1]. We report a case of CIVD with during fatal varicella in an immunocompromised 13-month-old child.

\section{CASE REPORT}

It was a 13-year-old girl, who was hospitalized in onco-pediatrics for the management of non-metastatic leg osteosarcoma. A dermatological opinion was requested for itchy vesicular lesions scattered on the trunk with a damage to the mucosa of a brutal installation in a feverish context. The clinical examination found a child with a fever at $40^{\circ}$ with the dermatological examination: skin lesions of different ages made of macules, purpuricerythemato-violaceous papules in places, hemorrhagic vesicles ombiliated at the centre resting on erythematous skin in places and purpuric by others, they were located on the scalp, trunk and 4 limbs with damage to the oral and genital mucosa (Figs. la-lc). The rest of the examination was normal.
The diagnosis of malignant chickenpox was made, treatment with Aciclovir was started, a biological checkup in search of visceral involvement had objectified craving disorders with renal failure. The evolution was marked by the development of cognitive disorders with confounding syndrome and the persistence off ever. She was then transferred to intensive care, where she continued to deteriorate. Clinical evolution was rapidly moving towards a multi-visceral failure picture with septic shock. The introduction of norepinephrine and the implementation of a extrarenal purification did not prevent the patient's death.

\section{DISCUSSION}

Varicella (chickenpox) is a highly contagious disease caused by infection with varicella-zoster virus (VZV). It results in a febrile, itchy, papulo-vesicular rash [1]. They occur mainly in early childhood. It's a benign disease that can be fatal as in our case [3]. Aapart from neonates, infants, and pregnant women, groups at higher risk for severe complications and death include immunocompromised subjects and adults. Varicella infection can cause morbidity and mortality in oncology patients [3]. Untreated varicella infection in children with cancer has been associated with a mortality of

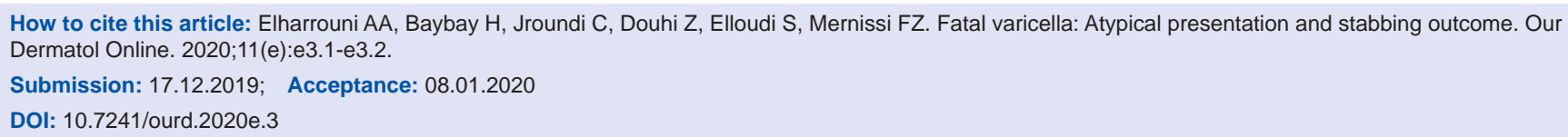




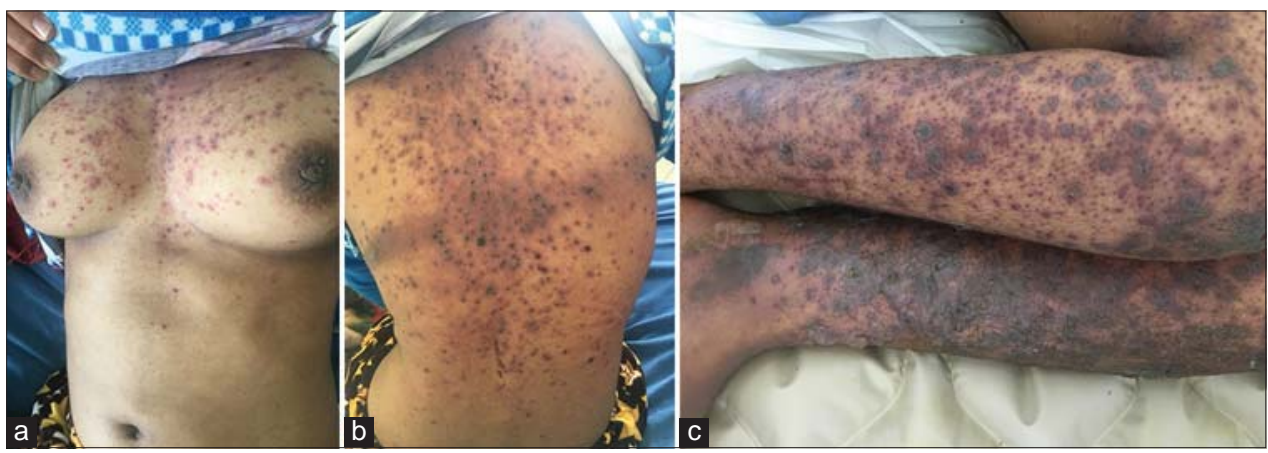

Figure 1: (a-c) Purpuric papules with umbilical hemorrhagic vesicles in the centerdiffuse all over the body.

approximately $7 \%$. The latter represented more than $3 / 4$ of children hospitalized for severe complications of chickenpox, including mortality is 0.4 deaths per $1,000,000$ children per year [1-3]. At this time, it should be remembered that vaccination is only recommended in children, without a history of varicella zoster virus (VZV) infection, with malignant hematopathy or solid tumour at a distance from chemotherapy, as well as that their siblings and caregivers in close contact with these children $[2,4,5]$.

\section{CONCLUSION}

Malignant chickenpox in immunocompromised children is a serious form that can combine several visceral disorders and jeopardize the vital prognosis, hence the interest of the clinic, which remains sovereign (anamnesis and careful dermatological examination) and of prevention through the restoration of vaccination in the immunocompromised child.

\section{REFERENCES}

1. Ogunjimi B, Van Damme P, Beutels P. Herpes zoster risk reduction through exposure to chickenpox patients: a systematic multidisciplinary review. PLoS ONE. 2013;8:e66485.

2. ECDC Report.Varicella vaccine in the European Union. European Centre for Disease Prevention and Control. 2014.

3. Tomonari A, Iseki T, Takahashi S, Ooi J, Takasugi K, Shimohakamada Y, et al. Varicella-zoster virus infection in adult patients after unrelated cord blood transplantation: a single institute experience in Japan. Br J Haematol. 2003;122:802-5.

4. Kriner P, Lopez K, Leung J, Harpaz R, Bialek SR; Centers for Disease Control and Prevention (CDC). Notes from the field: varicella-associated death of a vaccinated child with leukemia_California, 2012. MMWR Morb Mortal Wkly Rep. 2014;63:161.

5. Blumental S, Sabbe M, Lepage P; Belgian Group for Varicella. Varicella paediatric hospitalisations in Belgium: a 1-year national survey. Arch Dis Child. 2016;101:16-22.

Copyright by Alaoui Aicha Elharrouni, et al. This is an open access article distributed under the terms of the Creative Commons Attribution License, which permits unrestricted use, distribution, and reproduction in any medium, provided the original author and source are credited. Source of Support: Nil, Conflict of Interest: None declared. 